American Journal of Applied Sciences 5 (9): 1206-1211, 2008

ISSN 1546-9239

(C) 2008 Science Publications

\title{
Economical Investigation of ICECHP Using Gasohol-A Case Study for Iran
}

\author{
${ }^{1}$ Iman Baratian, ${ }^{2}$ Barat Ghobadian and ${ }^{1}$ Mohammad Ameri \\ ${ }^{1}$ Department of Energy Engineering, \\ Power and Water University of Technology (PWUT), P.O.Box: 16765-1719, Tehran, Iran \\ ${ }^{2}$ Tarbiat Modares University, P.O. Box: 14115-111 Tehran, Iran
}

\begin{abstract}
Energy is one of the most important factors in strategic planning throughout the world and can be considered as a dominant driving force for the industry and world economy. Biofuels development and applications specially in the form of Combined Heat and Power using Internal Combustion Engine (ICECHP) is wide-spreading which is the subject matter of the present paper as its economical investigation is concerned. The followed methodology is based on electricity direct pricing and actual annual benefit methods considering producers and consumers viewpoints. This investigation revealed that in the case of electricity direct pricing method, for the consumers the use of bioethanol gasoline blends (Gasohol) and ICE for CHP is uneconomical in all cases, and for the producers, E5 and E10 is economical. For the consumers, the case can be economical too with the grant of subsidy similar to the oil products. It can be concluded from the finding of the optimization process in the case of actual annual benefit method that market electricity price must be equal to its cost price and the subsidy must be devoted to the fuel instead of devoting it to the electricity. In this case, E5 is economical for the consumers and up to E15 is economical as for as producer is concerned.
\end{abstract}

Key words: ICE, CHP, ICECHP, electricity direct pricing, actual annual benefit

\section{INTRODUCTION}

Nowadays, energy is one of the most important factors for strategic planning in the world. Energy is the driving force of the industry and world economy. Among different types of energy, the fossil energy is the largest source of world energy.

At present most of the world energy resources utilization belong to few countries. For instance at, the end of the year 2005, Middle East countries owned 61.9 and $40.1 \%$ of oil and gas resources of the world respectively ${ }^{[1]}$.

After energy crisis in the year 1974, a new approach was created regarding the renewable energies which had a specific position in this approach. Economic control in the industrial countries and reduction of their dependency on the fossil energy resource of other countries, environmental pollution and this reality that fossil resource will come to the end one day and some other similar considerations were the reasons for the renewable energies to become the foundation of the energy sector policies. Renewable energy resources are: water, geothermal, biomass, solar energy, etc. Biomass is one of the renewable energy resources, which exists in different forms. One of these clean forms of renewable energy is biofuel that includes biodiesel, bioethanol, biomethanol, biogas, etc. These fuels are produced from agricultural and industrial waste, the prime cost of which is very low.

At present many technical problems of Combined Heat and Power with Internal Combustion Engine (ICECHP) using biofuel have been solved. In the developed countries, ICECHP is a well established method $^{[2]}$.

Corre and others have investigated the economical conditions of ICECHP in Mines School of Nantes by actual annual benefit method and concluded it's profitablity $^{[3]}$.

Bidini and his colleages performed the economical studies of ICECHP at the university of Prugia. They concluded that the pay back period was too long to be acceptable for this type of plant. They proposed the introduction of an absorption cooler, though expensive, that could raise the revenues considerably ${ }^{[4]}$.

Fischer presented the report of biomass CHP plants. He showed ICECHP which uses vegetable oil, bioethanol and biogas to be economical and has gained wide acceptance in the world market ${ }^{[2]}$.

Corresponding Author: Barat Ghobadian, Tarbiat Modares University, P.O. Box: 14115-111 Tehran, Iran 
Ameri and others have investigated the technical conditions of a CHP using various blends of gasohol in an IC engine and concluded that when the bioethanol in the blend increases, the output temperature and pressure, the flow availability, and the efficiency increase and the carbon monoxide content reduces. The results also have shown that the efficiency of CHP system is higher than the efficiency of SHP system. ${ }^{[5]}$

The information regarding economical investigation of ICECHP with bioethanol - gasoline blends (Gasohol) has not been published so far. Only some limited information about economical conditions of ICECHP using fossil fuel is available.

Therefore, in this paper the economic evaluation of ICECHP using bioethanol in Iran is presented. Economical justification is one of the main conditions in any project, therefore nowadays in addition to technical investigation of proposed project, the economical feasibility study is also carried out.

\section{MATERIALS AND METHODS}

Economical investigation is usually performed after the technical design for specific conditions. The specific technical designing for a CHP system has not been done so far in Iran. Therefore, the information of CHP system carried out in Mines school of Nant was used and some of these data were manipulated to suit the economical conditions of Iran. The economic conditions investigation was carried out in two stages. In the first step, by the means of the electricity direct pricing method, economic conditions were studied and compared for electricity price. Then in the second step, it was performed by means of AAB method. This investigation was carried out to consider the viewpoints of both producers and consumers.

Electricity direct pricing method: In CHP power plants, often two methods of pricing the output for economical investigation is used. The first one is direct pricing of electricity by taking financial credit for elimination of the auxiliary supply of heat. This method is often used for industrial CHP schemes. The second method is direct heat pricing by assuming values for the electricity purchased or sold. This method is more frequently used for district heating of CHP applications. Since the case is industrial ones, therefore in this study the first method is used ${ }^{[6]}$.

Williams $^{[8]}$ and Belding ${ }^{[9]}$ investigated the economics of CHP which involves a direct comparison between the pricing of electricity from CHP plant and that supplied from existing central power station. Kehlhofer $^{[10]}$ also presented a similar method. This approach has its validity mainly for independent CHP of industrial processes. Based on this method, the annual cost of the electricity produced is:

$$
\mathrm{P}_{\mathrm{e}}=\mathrm{C}+\mathrm{M}+(\mathrm{OM})
$$

In CHP systems, in addition to electricity produced, there is also supply of heat to process or district heating which can be assumed to be the same as an auxiliary heat source and supply it at the annual cost, which is saved. If the electrical power output is $\mathrm{W}$ and the annual plant operation hours is, $H$, the net unitized production cost of electricity for the CHP plant should be:

$$
\begin{aligned}
\left(\mathrm{Y}_{\mathrm{e}}\right)_{\mathrm{CG}}= & \frac{\left(\mathrm{P}_{\mathrm{e}}\right)_{\mathrm{CG}}}{\dot{\mathrm{W}} \mathrm{H}}=\frac{\left(\mathrm{C}_{\mathrm{CG}}-\mathrm{C}_{\mathrm{B}}\right)}{\dot{\mathrm{W}} \mathrm{H}} \\
& +\frac{\left(\mathrm{M}_{\mathrm{CG}}-\mathrm{M}_{\mathrm{B}}\right)}{\dot{\mathrm{W}} \mathrm{H}}+\frac{\left[(\mathrm{OM})_{\mathrm{CG}}-(\mathrm{OM})_{\mathrm{B}}\right]}{\dot{\mathrm{W} H}}
\end{aligned}
$$

The cost $M$ may be written as the product of the unit price of fuel, the rate of supply of energy in the fuel and the utilization factor. The quantity of the rate of supply of energy in the fuel is equal to $Q / \eta_{\mathrm{B}}$ where, $\mathrm{Q}$ is the heat load and $\eta_{\mathrm{B}}$ is the boiler efficiency of the original displaced heat source. Then if the cost of fuel is of the new plant and the displaced heat source is the same, i.e. $\varphi=\varphi_{\mathrm{CG}}=\varphi_{\mathrm{B}}$, then:

$$
\begin{aligned}
&\left(\mathrm{Y}_{\mathrm{e}}\right)_{\mathrm{CG}}= \frac{\left(\mathrm{P}_{\mathrm{e}}\right)_{\mathrm{CG}}}{\dot{\mathrm{W}} \mathrm{H}}=\frac{\left(\mathrm{C}_{\mathrm{CG}}-\mathrm{C}_{\mathrm{B}}\right)}{\dot{\mathrm{W}} \mathrm{H}} \\
&+\frac{\varphi}{\eta_{\mathrm{a}}}+\frac{\left[(\mathrm{OM})_{\mathrm{CG}}-(\mathrm{OM})_{\mathrm{B}}\right]}{\dot{\mathrm{W}} \mathrm{H}}
\end{aligned}
$$

and

$$
\eta_{\mathrm{a}}=\frac{\dot{\mathrm{W}}}{\dot{\mathrm{F}}-\frac{\dot{\mathrm{Q}}}{\eta_{\mathrm{B}}}}
$$

Actual annual benefit method: The Actual annual benefit $(\mathrm{AAB})$ has been presented by Silveira and Tuna $^{[11]}$ for the first time. The following equation which is based on the equations presented by Silveira and Tuna is used to calculate AAB:

$$
\mathrm{AAB}=\left(\mathrm{W}_{\mathrm{e}} \varphi_{\mathrm{e}}+\mathrm{Q} \varphi_{\mathrm{h}}-\mathrm{E}_{\mathrm{t}} \varphi_{\mathrm{F}}\right) \mathrm{H}-\mathrm{OM}-\mathrm{C}-\mathrm{I}-\mathrm{T}
$$

Energy costs are the most important parameters in equation (5). If $\mathrm{AAB}$ is the least, greater than zero and or greater than any amount defined by investor, then the project can be considered to be economical. 
Am. J. Applied Sci., 5 (9): 1206-1211, 2008

Table 1: The results of electricity direct pricing method

\begin{tabular}{llll}
\hline $\begin{array}{l}\text { Electricity Price } \\
\text { for Producer } \\
\text { (Rials per kWh) }\end{array}$ & $\begin{array}{l}\text { Electricity Price for } \\
\text { Consumer } \\
\text { (Rials per kWh) }\end{array}$ & $\begin{array}{l}\text { Electricity Price } \\
\text { Calculated } \\
\text { (Rials per kWh) }\end{array}$ & $\begin{array}{l}\text { Fuel } \\
\text { Blend }\end{array}$ \\
\hline 470 & 198 & 396.36 & E5 \\
470 & 198 & 440.95 & E10 \\
470 & 198 & 488.9 & E15 \\
470 & 198 & 539.91 & E20 \\
\hline
\end{tabular}

\section{RESULTS AND DISCUSSION}

In this part of the study, the results obtained by two methods are discussed.

Electricity direct pricing pethod: In different components, only the term $\frac{\varphi}{\eta_{a}}$ changes because the fuel cost changes when the fuel composition changes. Due to difference in the heat value of the bioethanol and gasoline, values of the system heat changes in different fuel blends. It is assumed that the change in the system heat is proportional to the heat value change of the fuel. So, $\eta_{\mathrm{a}}$ changes too. Quantities are substituted in equations ( $3 \& 4)$ to compute the final cost price of produced power. The obtained results are shown in Table 1.

As it is shown, electricity cost price for consumer in all cases is higher than electricity price in the market. So, for consumer in all cases, the use of bioethanol - gasoline blend and ICE for CHP is uneconomical. But two cases of E5 and E10 for producer, electricity cost price is less than electricity price in the market. So, for producer on these two cases, CHP with the use of bioethanol - gasoline blend in ICE is economical. Because of high difference between bioethanol price and gasoline price, the bioethanol has higher price. Increasing in bioethanol quantity in the blend results in increasing operation cost and electricity cost price. By this method, With the use of bioethanol gasoline in ICE for producer in two cases of E5 and E10 CHP is economical, but for consumer it is uneconomical. Since economic policies are determined by government and the market is controlled by government too, government could subsidize for fuel specially bioethanol and so it will be economical for consumers. Since the cost price of E5 and E10 for government is economical, government could pay the margin cost price of electricity to consumers as subsidy.

Actual annual benefit method: Due to granting subsidy in the Iranian energy market especially for fossil fuels, the cost price of produced power for producer and consumer is different. In this case, the
Table 2. The results of AAB method for the consumer

\begin{tabular}{ll}
\hline AAB & Fuel Blend \\
\hline 4013300 & E5 \\
-88970000 & E10 \\
-18270000 & E15 \\
-277320000 & E20 \\
\hline
\end{tabular}

Table 3: The results of AAB method for the consumer

\begin{tabular}{ll}
\hline AAB & Fuel Blend \\
\hline 4013300 & E5 \\
-88970000 & E10 \\
-18270000 & E15 \\
-277320000 & E20 \\
\hline
\end{tabular}

economic feasibility study is carried out for both viewpoints. For industrial consumers, the electricity price is different at different occasions. In this study it is assumed that the price of the electricity is 470 rials which is electricity cost price at power plant. Substituting the quantities in equation (5), actual annual benefit is computed and is shown in Table 2. As it shows for consumer, using E5 for ICECHP is economical while other blends aren't economical. It is important to know that the government subsidies are for gasoline only and not for bioethanol. If government grants subsidies for bioethanol, then the conditions will be very different.

Capital cost and fuel cost are the most important parameters in the case of economical results. Capital cost is constant with time, but fuel cost is affected by different factors and it changes. So, the importance of fuel cost is more than the importance of capital cost. Because of subsidy grants in Iranian energy market, the economic feasibility study for producer is as important as for consumer. Assuming that the price of electricity is 470 rials, recalculating the values in equation (5) and then the results are shown in Table 3. As shown in table 4 , all of the blends are economical. Increasing the amount of bioethanol in the blend, the AAB is reduced. This is due to increase in the fuel cost and a reduction in the heat quantity of the system. If government subsidizes for bioethanol, then, the economical conditions can be similar for both producers and consumers. Due to energy strategic, political and security reasons, this subject is very important. Even if production cost for gasoline or other fossil fuel is same as for bio or renewable fuel, the dependence upon the fossil fuel will be reduced and even can result in the reduction in the imports of fossil fuels or even export of the produced energy with higher price than for the Iranian market price.

Fuel and electricity prices are the most important parameters of the AAB. Figures 1- 4 show the surface of $\mathrm{AAB}$ as a product of fuel price and electricity price 


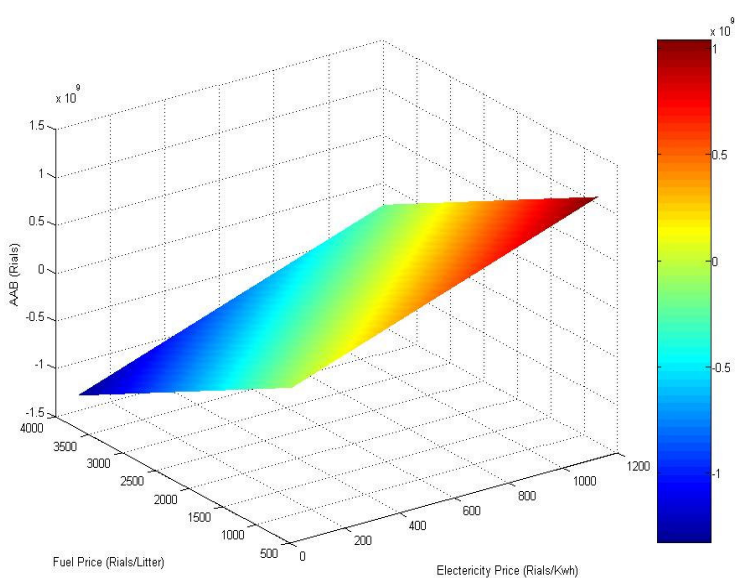

Fig. 1: $\mathrm{AAB}$ as a product of fuel price and electricity price for E5

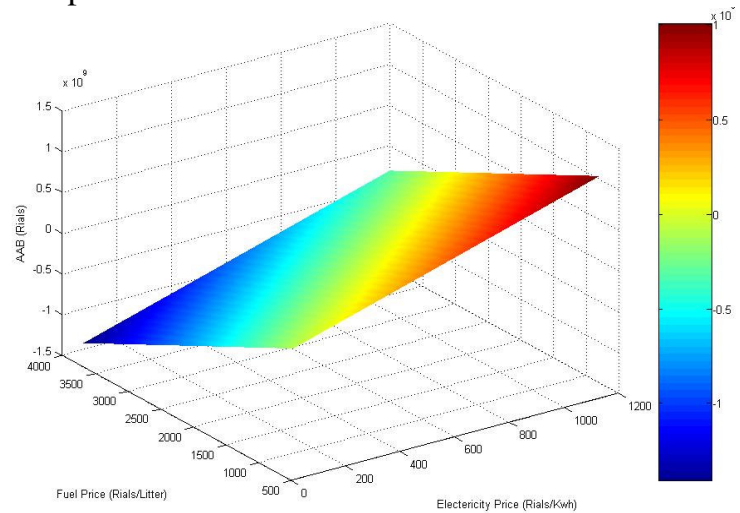

Fig. 2: AAB as a product of fuel price and electricity price for E10

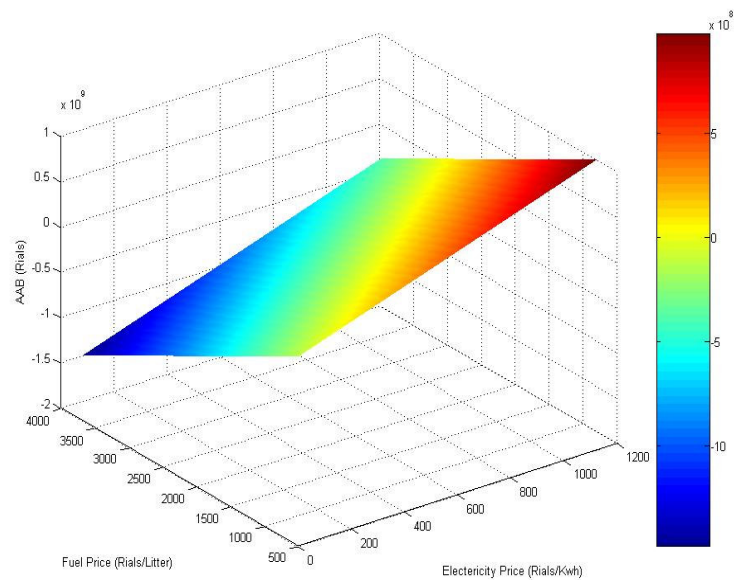

Fig. 3: AAB as a product of fuel price and electricity price for E15

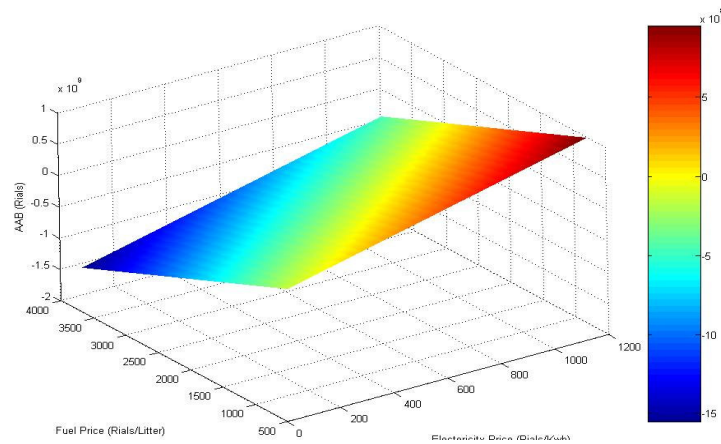

Fig. 4: $\mathrm{AAB}$ as a product of fuel price and electricity price for E20

for different blends of fuels. Horizontal surface shows the $\mathrm{AAB}$ equal to zero, therefore it is a boundary of economical and uneconomical region. The part of surface which is above the zero level is the economical zone. It is assumed that the other costs are constant and this figure shows the dependence of $\mathrm{AAB}$ to electricity price and blended fuel price. As it is shown, when fuel price is reduced and electricity price is increased, the value of the $\mathrm{AAB}$ shows an increasing trend. If a part or all of the electricity subsidy is being paid for fuel, then AAB will increase very considerably.

In this section, optimum point of maximum benefit is calculated for two viewpoints in the formulization of the problem. Objective function is defined as sum of the two $\mathrm{AAB}$ function for producer and consumer. In formulization, the subsidy of energy for electricity and fuel is assumed. AAB function for consumer is same as equation (5). For the producer, $\mathrm{AAB}$ function assumes the electricity subsidy as $S_{e}$ and the fuel subsidy as $S_{f}$ :

$$
\begin{aligned}
\mathrm{AAB}_{\mathrm{P}}= & {\left[\mathrm{W}_{\mathrm{e}}\left(\varphi_{\mathrm{e}}+\mathrm{S}_{\mathrm{e}}\right)+\mathrm{Q} \varphi_{\mathrm{h}}-\mathrm{E}_{\mathrm{t}}\left(\varphi_{\mathrm{f}}+\mathrm{S}_{\mathrm{f}}\right)\right] \mathrm{H} } \\
& -\mathrm{OM}-\mathrm{C}-\mathrm{I}-\mathrm{T}
\end{aligned}
$$

Objective function assumes the same weight for both consumer and producer $^{[12]}$ :

$$
\mathrm{AAB}=\mathrm{AAB}_{\mathrm{C}}+\mathrm{AAB}_{\mathrm{P}}
$$

Variables in equation (7) are: electricity price, electricity subsidy, fuel price and fuel subsidy. For optimization of equation, first of all the boundary conditions must be determined. In the first condition, variables must be positive i.e.:

$$
\begin{aligned}
& \varphi_{\mathrm{e}} \geq 0 \\
& \varphi_{\mathrm{f}} \geq 0
\end{aligned}
$$


Am. J. Applied Sci., 5 (9): 1206-1211, 2008

Table 4: The results of AAB method for producer

\begin{tabular}{lll}
\hline AAB & & Fuel Blend \\
\hline 274050000 & & E5 \\
181070000 & & E10 \\
87338000 & & E15 \\
-7275500 & E20 \\
\hline & $\mathrm{S}_{\mathrm{e}} \geq 0$ & \\
& & \\
& $\mathrm{~S}_{\mathrm{f}} \geq 0$ &
\end{tabular}

The sum of the price and subsidy of electricity must be equal to its cost price. This condition in a country such as Iran is correct, because supply, demand and price in energy market are independent and government determines the energy price. Total price conditions are:

$$
\begin{aligned}
& \varphi_{\mathrm{e}}+\mathrm{S}_{\mathrm{e}}=470 \\
& \varphi_{\mathrm{f}}+\mathrm{S}_{\mathrm{f}}=3600
\end{aligned}
$$

The actual gasoline price assumed is 3600 rials. Benefits for producer and consumer must be positive. These conditions are the two principal conditions of the optimization.

$$
\begin{aligned}
& \mathrm{AAB}_{\mathrm{P}} \geq 0 \\
& \mathrm{AAB}_{\mathrm{C}} \geq 0
\end{aligned}
$$

The value of $\mathrm{Q}$ and $\varphi_{\mathrm{f}}$ for different quantities of bioethanol blends are different. Because the change in fuel blend results in the change in blend heat values, therefore $\mathrm{Q}$ changes and hence fuel cost changes too. So, for E5, E10, E15 and E20 equation (7) will be as follow respectively:

$$
\begin{aligned}
\mathrm{AAB}= & 1985600 \varphi_{\mathrm{e}}-804828 \varphi_{\mathrm{f}}+992800 \mathrm{~S}_{\mathrm{e}} \\
& -387.59 \mathrm{~S}_{\mathrm{f}}+371423596.8 \\
\mathrm{AAB}= & 1985600 \varphi_{\mathrm{e}}-835896 \varphi_{\mathrm{f}}+992800 \mathrm{~S}_{\mathrm{e}} \\
& -387.59 \mathrm{~S}_{\mathrm{f}}+331688937.6 \\
\mathrm{AAB}= & 1985600 \varphi_{\mathrm{e}}-865000 \varphi_{\mathrm{f}}+992800 \mathrm{~S}_{\mathrm{e}} \\
& -387.59 \mathrm{~S}_{\mathrm{f}}+296833248 \\
\mathrm{AAB}= & 1985600 \varphi_{\mathrm{e}}-892500 \varphi_{\mathrm{f}}+992800 \mathrm{~S}_{\mathrm{e}} \\
& -387.59 \mathrm{~S}_{\mathrm{f}}+266029584
\end{aligned}
$$

Using Lingo software and Simplex method, equations 16 to 19 are optimized linearly. According to the results for all blends, no feasible solution could be
Table 5: The results of the first case using producer benefit condition

\begin{tabular}{lllll}
\hline E5 & E10 & E15 & E20 & Variable \\
\hline- & - & - & - & $A A B($ Rials $)$ \\
470 & 470 & 470 & 470 & $\varphi_{e}\left(\frac{\text { Rials }}{k W h}\right)$ \\
0 & 0 & 0 & 0 & $\varphi_{f}\left(\frac{\text { Rials }}{\text { Liter }}\right)$ \\
0 & 0 & 0 & 0 & $S_{e}\left(\frac{\text { Rials }}{k W h}\right)$ \\
3600 & 3600 & 3600 & 3600 & $S_{f}\left(\frac{\text { Rials }}{\text { Liter }}\right)$ \\
\hline
\end{tabular}

Table 6:The results of the first case whitout producer benefit condition

\begin{tabular}{lllll}
\hline E5 & E10 & E15 & E20 & Variable \\
\hline 1303260000 & 1263526000 & 1228670000 & 1197866000 & $A A B($ Rials $)$ \\
470 & 470 & 470 & 470 & $\varphi_{e}\left(\frac{\text { Rials }}{k W h}\right)$ \\
0 & 0 & 0 & 0 & $\varphi_{f}\left(\frac{\text { Rials }}{\text { Liter }}\right)$ \\
0 & 0 & 0 & 0 & $S_{e}\left(\frac{\text { Rials }}{k W h}\right)$ \\
3600 & 3600 & 3600 & 3600 & $S_{f}\left(\frac{\text { Rials }}{\text { Liter }}\right)$
\end{tabular}

found out for the problem. Results are shown in Table 5 . For these results equation (14) in which producer benefit must be positive, is not valid. Since Iranian economy is government based, it eliminates equation (14) and hence optimization is converted to maximization sum of consumer and producer benefit. In fact, this is the maximization of consumer benefit and minimization of producer loss. Results of optimization for the new condition is shown in Table 6.

As shown, with this condition, optimization problem obtains feasible solution. In this case electricity price and fuel subsidy are maximized and fuel price and electricity subsidy are minimized. This is obviously a linear optimization.

The minimum value for the variables was zero in optimization. In the second and the third cases, the minimum value for fuel price is equal to 600 and 800 rials per liter respectively repeating optimization again. The results of optimization process is shown in Table 7 .

As it is shown, for $\eta_{\mathrm{f}} \geq 600$ a feasible solution is find out for optimization problem. But for $\eta_{\mathrm{f}} \geq 800$ no feasible solution could be find out for the optimization problem. In this case equation (15) is not valid. So, the results shown in Table 7 , shows the maximum of objective function that resulted in the minimum of the consumer losses. These figures are the boundary for the feasible solution of fuel price. Increasing in fuel price results in increasing the consumer loss and producer benefit which is against optimization purpose. Fuel price shown in Table 7 in the third case is the upper boundary of the feasible solution. 
Am. J. Applied Sci., 5 (9): 1206-1211, 2008

Table 7. The results of the second and third cases

\begin{tabular}{|c|c|c|c|c|c|}
\hline E5 & E10 & E15 & E2 & Variable & Case \\
\hline 820596000 & 762220600 & 709902500 & 662598800 & $A A B($ Rials $)$ & Second Case ( The Minimum of Fuel Price Equal to 600 Rials) \\
\hline 470 & 470 & 470 & 470 & $\varphi_{e}\left(\frac{\text { Rials }}{k W h}\right)$ & \\
\hline 600 & 600 & 600 & 600 & $\varphi_{f}\left(\frac{\text { Rials }}{\text { Liter }}\right)$ & \\
\hline 0 & 0 & 0 & 0 & $S_{e}\left(\frac{\text { Rials }}{k W h}\right)$ & \\
\hline 3000 & 3000 & 3000 & 3000 & $S_{f}\left(\frac{\text { Rials }}{\text { Liter }}\right)$ & \\
\hline- & - & - & - & $A A B($ Rials $)$ & Third Case ( The Minimum of Fuel Price Equal to 800 Rials) \\
\hline 470 & 470 & 470 & 470 & $\varphi_{e}\left(\frac{\text { Rials }}{k W h}\right)$ & \\
\hline 698 & 720 & 736 & 748 & $\varphi_{f}\left(\frac{\text { Rials }}{\text { Liter }}\right)$ & \\
\hline 0 & 0 & 0 & 0 & $S_{e}\left(\frac{\text { Rials }}{k W h}\right)$ & \\
\hline 2902 & 2880 & 2864 & 2852 & $S_{f}\left(\frac{\text { Rials }}{\text { Liter }}\right)$ & \\
\hline
\end{tabular}

\section{CONCLUSION}

In this study, the economical investigation of ICECHP using gasohol was carried out by two methods i.e.: electricity direct pricing and actual annual benefit. Electricity direct pricing method resulted in ICECHP with gasohol that was uneconomical for consumer and for producer with E5 and E10 it was economical. Government could subsidize for fuel specially bioethanol and so this could be economical for consumers. Using actual annual benefit method resulted in ICECHP to be economical E5 for consumer and up to E20 for producer. From the optimization results, it could be concluded that market electricity price must be equal to its cost price and its subsidy must be devoted to fuel instead of electricity.

\section{REFERENCES}

1. Davies, P., 2006. BP Statistical Review of World Energy. available on: http://www.bp.com

2. Fischer, J., 2003. Technologies for Small Scale Biomass CHP Plant - an Actual Survey. Biomass Information Center. available on: http://www.biomass-info.net.

3. Core, O. L., G. Brecq, M. Tazerout, 2002. Thermodynamic Analysis Based on Energy Structure for Combined Heat and Power. Applied Thermal Engineering .22: 561-566.
4. Bidini G., U. Desideri, S. Saeta, P.P. Bocchini, 1998. Internal Combustion Engine Combined Heat and Power Plants: Case Study of The University of Perugia Power Plant. Applied Thermal Engineering. 8 (6): 401-412.

5. Ameri M., Ghobadian B., Baratian I., Technical Comparison of a CHP Using Various Blends of Gasohol in an IC Engine., Renewable Energy (2007), doi:10.1016/j.renene.2007.09.015

6. Horlock. J.H., 1987. Cogeneration-Combined Heat and Power (CHP). First edition. U.K. Pergamon Press.

7. Iranian Power Ministry, 1983. Iran Energy Balance 1983. Iranian Power Ministry Press. Tehran.

8. Williams R.H., 1978. Industrial Cogeneration. Annual Review Energy, .3: 333-356.

9. Belding J.A., 1982. Cogeneration. First edition, Massachusett. MIT Press, Cambridge, Mass.

10. Kehlhofer R.,1980. Comparision of Power Plants for Cogeneration of Heat and Electricity. Brown Boveri Review, 8-80: 504-511.

11. Silveira, J.L., and C.E. Tuna, 2000. Thermodynamic Analysis Method for Optimization of Combined Heat and Power Systems. ECOS 2000 Proceeding 1: 233-244.

12. Taha H.A., 1976. Operations Research; an Introduction. Second edition, Macmillan Publishing Co., Inc., 